\title{
El léxico de Jaume Vicens Vives (1910-1960) (II)
}

\author{
FRANCISCO ABAD \\ UNED
}

Resumen: Tratamos del empleo de voces y de las nuevas acepciones que encontramos en escritos de Jaime Vicens, como continuación de un trabajo publicado en el número XIV de esta misma revista.

Palabras clave: Jaume Vicens Vives; Romanticismo; burgués; capital; obrero; pequeña burguesía.

Resum: Tractem de l'ús de mots i de les noves accepcions que podem trobar en escrits de Jaume Vicens, com a continuació d'un treball anterior, publicat en el número XIV d'aquesta revista.

Paraules clau: Jaume Vicens Vives; Romanticisme; burgès; capital; obrer; petita burgesia.

En 2010 se cumplen cien años del nacimiento de este egregio historiador y hombre de empresa, y cincuenta de su muy temprana muerte; de momento se ha publicado un bello Album que contiene algunos textos propios, juicios sobre la persona y su obra, fotos, datos cronológicos, etc., todo ello bien cuidado por Josep M. Muñoz Lloret (2010); asimismo se han publicado los mapas dibujados por Vicens de un Atlas histórico-universal que tenía preparado (2010).

En el número XIV (pp. 327-339) de esta revista tenemos hecha ya una primera entrega del presente trabajo, y allí señalábamos cómo desde el punto de vista filológico que nos es propio, cabe ordenar algunas de las ideas, concepciones y definiciones hechas por nuestro autor tal como se manifiestan según un léxico o vocabulario concreto: cuando escribe en este caso en castellano, Vicens acuña y lexicaliza con determinados vocablos y expresiones su mundo de ideas y de interpretaciones historiográficas, y son algunas de tales lexías las que vamos a ver; las ordenamos alfabéticamente.

Pretendemos llevar a cabo una modesta aportación de materiales para el Diccionario histórico de la lengua española; estamos desde luego ante un autor 
de mucho relieve —en castellano y en catalán— del segundo tercio del siglo XX.

De manera particular nos referimos ahora a conceptos y voces que tienen que ver con la historia contemporánea, especialmente con el Ochocientos al que Jaume Vicens Vives dedicó los años últimos de su vida; algunas referencias sobre Diccionarios las hacemos a obras de tal género bien conocidas.

anarquismo, anarquistas. « $\mathrm{Al}$ otro lado — caracteriza Vicens- del mítico prestigio hegeliano atribuído por Marx al Estado, se situaron los anarquistas colectivistas, esto es, los que creían que la transformación social se realizaría mediante la supresión del Estado por la colectividad económica bien organizada. Este grupo se caracteriza por su extraordinario idealismo, por su bondad intrínseca, deformada luego por los procedimientos drásticos y terroristas puestos en práctica por los adeptos del anarquismo. Causa sensación comprobar que los principales teorizantes fueron tres rusos: Mikhail Bakunin (1814-1876), Peter Kropotkin (1842-1921) y León Tolstoi (1828-1910), los tres aristócratas. El primero, por un tiempo adscrito al socialismo internacional, renunció luego a todo compromiso y condujo la más violenta campaña de exaltación terrorista: la que llamó «propaganda de los hechos». A él cabe imputar pues la oleada de atentados anarquistas con que finalizó el siglo. En cambio el príncipe Kropotkin renunció a toda agresión contra el individuo, y aunque preveyó una última ofensiva violenta del proletariado contra el Estado, se opuso a todo régimen de terror; el colectivismo comunista aseguraría un régimen de paz al Mundo. Tolstoi acentuó la nota negativa ante la violencia: su profundo cristianismo le inducía en definitiva a la paz y la caridad completa, en un acto de entrega del individuo a la sociedad. El anarquismo prendió sobre todo en los países eslavos y latinos. El revisionismo marxista entre las poblaciones germánicas de Europa. Dos hechos cartografiables, que se adaptan a la psicología social de estas dos grandes divisiones raciales y económicas del continente» $(1952,394)$.

En una exposición elemental escribe el autor: «Frente al marxismo se desarrolló una corriente de emancipación social que preconizaba la negación del Estado, la no intervención en las luchas políticas, el recurso al alzamiento armado, la destrucción de la sociedad por el terror. [...] El anarquismo había desembocado hacia el callejón sin salida del terrorismo, cuando vino a empalmar en el sindicalismo revolucionario surgido en los países latinos» (1945/1960, 468469).

Elías Zerolo define en 1895 la voz anarquismo como 'sistema, opinión de los anarquistas', y anarquista en tanto 'persona que desea o promueve la anarquía'. El DRAE incorpora en el Suplemento de su edición de 1899 la primera palabra: 'conjunto de doctrinas de los anarquistas', pero no inclye la voz anarquista que sí estará en el mismo DRAE de 1914: "persona que desea o promueve la anarquía'; si no nos equivocamos, esta definición la tomó la Academia de Aniceto de Pagés, quien a su vez la tomó de Zerolo, o bien la Academia la tomó directamente de Zerolo.

burgués, ideal; burguesas, clases; burguesía industrial y financiera. Jaume Vicens emplea las voces y lexías «cultura burguesa»; «burguesía»; «menta- 
lidad burguesa»; «potencialidad burguesa»; etc. Reunimos algunos pasajes que documentan varias de tales lexías y que importan conceptualmente: en términos generales hace una presentación en la que describe cómo «la burguesía, la célula viva del siglo XIX, cristaliza definitivamente en una clase social determinada. Ya no es el confuso Tercer Estado de 1789. Se trata de las personas que, viviendo en las ciudades, poseen medios económicos suficientes para vivir de modo independiente. El burgués típico de esta época es el que se dedica al comercio, las finanzas o la industria (capitalista). Algunos llegan a acumular grandes riquezas y reciben títulos honoríficos; otros viven más modestamente. Unos y otros poseen acciones y rentas del Estado o industriales (rentistas). De la burguesía salen también los miembros de las profesiones liberales, los cuales pueden considerarse englobados en ella (1943, 554-555).

En otro momento y sobre una larga duración de la historia que es la de un siglo XIX amplio, escribe Vicens: «Desde la época de la Restauración las clases burguesas de Europa, a través de dos agitaciones revolucionarias, eliminan de la escena política a los últimos residuos de la aristocracia feudal y se instalan en los gabinetes y los parlamentos; desde allí dirigen a su antojo las transformaciones sociales y económicas, las relaciones extranjeras y la política colonial. El mundo es suyo y recibe de ellas un sello indeleble. Pero si la acción política de la burguesía es tan ostensible, aún lo es más su contribución a la cultura del siglo XIX. [...] Existe pues de 1815 a 1914 una cultura burguesa, de trazos firmes y característicos» $(1952,364)$.

Estas «clases burguesas» 0 «burguesía» poseen como propio un «ideal burgués», a saber: «El ideal burgués del siglo XIX afluye y refluye entre dos polos que le son caros y paradójicamente se autoeliminan: libertad y orden. Libertad en primer lugar para organizar sus negocios, evitando las menores intervenciones del Estado; luego, para intervenir en la vida política del país e imponer, desde el Parlamento, la fiscalización de los actos del gobierno y la administración de los gastos del Estado; en fin, libertad para exponer las ideas e imponerlas mediante los derechos de reunión, asociación y prensa. Orden, en primer lugar, para defender la propiedad y, subsiguientemente, los intereses vinculados a ella; luego, para evitar los conflictos que perjudican el desarrollo normal de las empresas y negocios. [... Para la burguesía] libertad significa, ante todo, libertad individual dentro del orden social» $(1952,364-365)$.

Además de esos «ideales» burgueses, las clases burguesas tienen otros componentes de «mentalidad», y así llevan consigo «dos conceptos»: «Uno de ellos, el de progreso, otro, el de cristianismo depurado a lo volteriano. La fe en el progreso - concretamente, en el progreso de las ciencias que se confabula con el de la técnica industrial — ha substituído definitivamente en ella a la fe religiosa. [...] Para la burguesía del XIX el cristianismo ya no es una fe, sino una forma de arte» $(1952,365)$.

Un dato de estamentalidad social es también el de que «los Estados halagaron la vanidad de los grandes industriales concediéndoles títulos nobiliarios» (Ibid.), y efectivamente el pacto burgués-nobiliario llevó a la integración de las fortunas en las minorías nobiliarias; es lo que Galdós y otros escritores novelaron algunas veces, según han analizado Carlos Blanco Aguinaga, F. Abad, etc. 
En otros términos ha expuesto nuestro autor el carácter burgués del XIX, y ha designado a su burguesía como «industrial y financiera»: «El siglo XIX es la época burguesa por excelencia. La burguesía domina en el Estado y las asambleas parlamentarias; detenta las bancas, las fábricas y los consejos de administración de las sociedades anónimas; posee la prensa y las imprentas; enseña y aprende en las [U]niversidades; escribe, pinta y esculpe. No se le escapa la dirección de ninguna actividad práctica o espiritual. Está en todas las brechas. [...] Es la burguesía industrial y financiera. Está convencida de que promueve la felicidad general al desarrollar la economía, preconizar su régimen de igualdad civil y libertad política, destronar los errores de un pasado tradicionalista y clerical. Ella ha hecho la revolución en las instituciones políticas y jurídicas, ha emancipado a los campesinos de la jurisdicción señorial y a los artesanos de la opresión gremial $(1945 / 1960,466)$.

Burgués queda definido en el Diccionario académico ya en 1884 como 'ciudadano de la clase media', y burguesía en tanto 'cuerpo ó conjunto de burgueses ó ciudadanos de la clase media', definiciones tomadas a la letra tanto por E. Zerolo como por Pagés.

burguesa, economía. En otro significado de lo burgués, que afecta no ya al Ochocientos sino a una duración multisecular, Vicens propone: «Debe entenderse por economía burguesa el régimen de producción, transporte y distribución de los bienes nacido en las ciudades europeas en el siglo XII y mantenido hasta la actualidad en buena parte del mundo. Dicho régimen se basa en el predominio del comercio y la industria sobre la agricultura, en la expansión económica mediante el empleo de la moneda y en la distribución unilateral de los medios de producción, que son acumulables y transmisibles por herencia. [...] Realmente una economía de tipo burgués es incomprensible sin un capital que inicie el ciclo de la producción de bienes y se lucre de su venta y consumo. Pero el capitalismo es sólo una parte del contenido económico burgués, pues éste incluye, así mismo, un espíritu de investigación y aventura, un estilo de vida y un deseo de progreso científico y libertad cultural» $(1958,34)$.

cambio de siglo, fin de siglo. En referencia a los lustros de transición del Ochocientos al siglo XX, Vicens hace empleo de estas fórmulas verbales, y vemos así: «En los decenios que cabalgan sobre el cambio de siglo, la pluralización de los sistemas llega al grado máximo.El positivismo degenera en un «empiri[o]criticismo» [...]. Momento de crisis, de revolución de las conciencias, en que la revalorización de lo irracional, lo metafísico y lo religioso, la afirmación de los valores antimecanicistas, como los históricos, [...] parecen propender al establecimiento de una nueva ideología de Occidente» $(1952,406)$.

En otro lugar y con punto de vista complementario, ha escrito nuestro autor que entre 1895 y 1914 «el mundo conoció una edad feliz: el dorado fin de siglo burgués» (1945/1960, 466).

capital. Jaume Vicens llega realmente a definir qué es capital, y construye luego su discurso con varias fórmulas léxicas según vamos a ver. «Todo elemento de producción - desarrolla — es un capital, algo de que se dispone para obtener un beneficio. Primariamente el hombre dispone de dos fuentes de capi- 
tal: el físico, acumulado en sus músculos, y el intelectual, afincado en su cerebro. La máquina representa un capital, en cuanto procura un beneficio y en cuanto es resultado de un trabajo anterior para construirla. [...] Toda actividad económica necesita el impulso de un capital precedente. [...] La noción de capital implica otra no menos importante: el de la propiedad del capital. Ésta puede ser privada o colectiva, declarada o anónima, particular o estatal».

Nuestro autor traza también la evolución histórica de lo que ha sido capital:

a) el «capital agrario», o sea, el "patrimonio necesario para hacer fructificar los campos (casa, aperos, animales de labor y educación agrícola)';

b) el «capital mercantil», esto es, 'las inversiones hechas en el comercio de los bienes de consumo, en particular del comercio transmarítimo';

c) el «capital industrial», que es el exigido para 'la instalación de una fábrica, la compra de maquinaria y el pago de técnicos adecuados para su buen uso'. En este estadio la industria subordina la agricultura, el comercio y la banca a sus necesidades»;

d) ocurre en fin que «el capital evoluciona hacia el capitalismo financiero». En este estadio 'domina la noción de capital=dinero. El dinero tiene que rentar' (1958, 48-49).

Otra explicación del autor dice así: «La revolución industrial exigió desde el primer momento grandes capitales. [...] Para que el capitalismo industrial de la primera mitad del siglo XIX pudiera realizar la tarea que se le exigió más tarde, fue preciso que le prestara apoyo el capitalismo financiero, o sea la organización capaz de llevar el dinero privado a las sociedades anónimas industriales y comerciales en forma de acciones» (1945/1960, 464).

capitalismo; gran capitalismo. Jaume Vicens trata de las formas económicas del siglo XIX y entonces expone: «La industria dirige y condiciona la vida comercial y financiera del mundo. Este rasgo es determinante en la constitución del gran capitalismo. [...] La economía europea cristaliza en un tipo definitivo caracterizado por la empresa, la racionalización del negocio, la concentración de la vida económica y los capitales, y la ruptura de toda traba estatal [...]. Preocupación esencial del gran capitalismo es la totalización de la vida económica: control de las materias primas, transporte de todo género de mercancías, producción en serie y venta en sucursales de los productos fabricados. [...] Gran capitalismo significa imperialismo económico» (1943, 552-553).

«El capitalismo europeo - expone nuestro autor- había recibido su estructura básica en los siglos XVII y XVIII. [...] Las formas capitalistas, tanto en la agricultura como en el comercio, la industria y las finanzas, estaban ya fijadas y eran capaces de ulterior progreso. Sin embargo, a principios del Diecinueve nadie podía sospechar que este desarrollo conduciría muy pronto al Gran Capitalismo, sistema en que la industria (la producción) condiciona los demás factores de la vida económica, social y política hasta dominarlos por completo. Este cambio trascendental se registró entre 1830 y 1870, en cuya última fecha puede ya hablarse de iniciación de la época del Gran Capitalismo»; el factor decisivo de tal transformación - añade el autor - fue la 'ciencia aplicada a la economí- 
a', es decir, la técnica: encontramos aquí una verdadera definición de «técnica» que hace al paso el historiador $(1952,378)$. «Especialización — sintetiza asimismo-, producción en serie y concentración, tales fueron las formas industriales del Gran Capitalismo» (1952, 380).

En el texto Polis que venimos citando de pedagogía histórica, expone nuestro autor sobre estos mismos asuntos: «El capitalismo descansó en dos ideas básicas: que el Estado había de prescindir de cualquier intervención en la vida económica (librecambismo), y que la máquina era un instrumento del proceso de producción destinado a hacer fructificar el capital y transformarlo en renta para el accionista o el propietario de la fábrica (rentabilidad capitalista).[...] La abundancia de producción conducía al acumulamiento de mercancías y a la paralización subsiguiente de las fábricas. Los obreros eran despedidos en masa y algunos fabricantes se arruinaban. Después de dos o tres años de crisis, el mercado volvía a animarse y de nuevo funcionaban industrias y talleres» (1945/1960, 465-466).

El Diccionario de Alemany y Bolufer (1917) define capitalismo como el 'régimen económico de la producción, fundado en la propiedad individual de los capitales'; el DRAE de 1925 —una de las ediciones importantes de entre las del siglo XX- establece semejantemente que se trata del 'régimen económico fundado en el predominio del capital como elemento de producción y creador de riqueza'.

capitalista, economía. Tras los estadios que quedan vistos del capital agrario y el mercantil, Vicens concreta cómo «la tercera etapa del desarrollo económicosocial del Occidente de Europa se extiende de mediados del siglo XVIII a principios del siglo XX[,] y recibe el nombre de capitalista en sentido estricto. Corresponde a la expansión de la máquina como resultado de la Revolución industrial y a la aparición de un amplio grupo social obrero, denominado proletariado por sus condiciones de vida, trabajo y emolumentos» $(1958,39)$.

comunista, colectivismo. Ya está mencionado el pasaje de nuestro autor que dice cómo «el príncipe Kropotkin [...] se opuso a todo régimen de terror; el colectivismo comunista aseguraría un régimen de paz al Mundo»; tenemos aquí empleado el adjetivo «comunista», en un significado antiguo de la voz.

Efectivamente la palabra comunismo figuraba ya en los Diccionarios académicos desde el último tercio del Ochocientos — desde 1869-, en el sentido tradicional de 'doctrina por la cual se quiere establecer la comunidad de bienes, y abolir el derecho de propiedad'. Estamos ante una voz que aparece por ej. en Nicomedes-Pastor Díaz, quien en la «lección décimatercera» de su curso en el Ateneo de Madrid sobre «Los problemas del socialismo» (1848-1849), proclama: «La asociación primitiva del trabajo para crear los primeros capitales y la primera subsistencia, si no viniera de Dios como vienen la sociedad y las lenguas, no hubiera sido más que un comunismo bárbaro, mísero y precario».

Es voz que aparece por igual repetidas veces en el San Francisco de Asís (1882) de doña Emilia Pardo Bazán, y justamente en la acepción aludida:

El comunismo — escribe doña Emilia - existe latente en todos tiempos [...]. Siempre que la multitud solicita que se distribuya entre la mayoría un bien que 
posee la minoría, hay petición comunista [...] El moderno comunismo, sin prescindir de la omnímoda libertad política y religiosa, reclama principalmente la partición de la riqueza [...] El comunismo no pide derechos para el individuo, sino para la colectividad.

Trata en un momento nuestra autora de las que denomina «herejías del siglo XIII», y escribe asimismo que «en los dulcinistas y fraticelos [prepondera] el comunismo social».

A su vez en la «cuarta serie» de los Episodios nacionales galdosianos hemos encontrado alguna vez la palabra en este sentido tradicional; leemos así por ej.: «que se decretara el socialismo y el comunismo y los falansterios», o «no vieron señal ninguna de propiedad personal. Todo era de todos, del pueblo [...] El propio comunismo vieron y comprobaron [...]». Joaquín Costa explica por su parte cómo Juan Luis Vives sienta «que el comunismo primitivo fue abolido e individualizada la posesión del suelo, para que los holgazanes no explotaran a los hacendosos, viviendo ociosamente del trabajo de éstos».

cártel. En varios de los textos que venimos citando hace empleo Jaume Vicens de los vocablos cártel y trust (e. gr., 1943, 552; 1958, 55); en la edición del DRAE inmediatamente anterior al texto del año 43 al que aludimos no figura la acepción que nos importa de la presente voz, pero en la edición dos años anterior a la segunda obra de nuestro autor aludida, se define la misma palabra como 'convenio entre varias empresas similares para evitar la mutua competencia y regular la producción y los precios en determinado campo industrial'. Cártel figurará pues en el aludido Diccionario académico; en nuestros días el $D E A$ de Seco-Andrés-Ramos hace esta definición: 'asociación internacional de empresas independientes con actividades análogas, que tiene por objeto monopolizar la producción y distribución de un producto y controlar los precios'.

fábrica. Se trata de una voz de que hace uso naturalmente Vicens, el cual la parafrasea como 'trabajo en un taller colectivo' $(1958,44)$; el aludido DRAE del año 56 establece como fábrica el 'lugar donde se fabrica una cosa'. De todas formas nuestro autor especificó (Ibid., 42) cómo «la fábrica propiamente dicha» supone la «combinación de unos dispositivos mecánicos a una máquina de vapor», según volveremos a ver.

Debemos a José Antonio Maravall un estudio en el que se analizan las acepciones de la palabra, y este historiador concluye: «A partir de la obra de Álvarez Ossorio en la segunda mitad del XVII, el concepto moderno de fábrica se ha introducido en el léxico castellano»; Maravall menciona también un pasaje esclarecedor - más tardío - de Campomanes, el cual escribe que se llaman fábricas «aquellas manufacturas complicadas que constan de varias clases de operarios, por cuyas manos pasan gradualmente las manufacturas, hasta llegar a su debida terminación» (J. A. Maravall 1973, 24-25).

Una fábrica era aún para el Diccionario de Autoridades un 'paráge destinado para hacer siempre alguna cosa: como la fabrica del tabaco, la fabrica de los paños' pero en el DRAE de 1791 es más claramente el 'lugar destinado para fabricar alguna cosa'. El lexicógrafo Ramón Joaquín Domínguez daba el signifi- 
cado de el 'establecimiento, oficina, local destinado para fabricar alguna cosa', como «fábrica de paños», «fábrica de fideos», ..., y en fabricar define 'trabajar ó elaborar cualquier clase de artefacto'.

maquinismo. Elementalmente se llama maquinismo al fenómeno de que 'la máquina substituyó de hecho al operario en todo el proceso de la producción' $(1954 / 1960,220)$.

«El siglo XIX — describía y escribía además Vicens- asistió a un fulgurante desarrollo del maquinismo. [...] La máquina de vapor y los altos hornos son los emblemas heráldicos de la centuria. Aquella se aplicó a toda instalación industrial que requiriera un manantial de energía, y así nació la fábrica propiamente dicha, como combinación de unos dispositivos mecánicos a una máquina de vapor. [...] Dos hechos nuevos (navegación y locomotora a vapor) revolucionaron el transporte desde 1840. La máquina vencía al tiempo y reducía el espacio de la tierra. En cuanto al hierro, sus grandes adelantos corresponden a la segunda mitad del siglo XIX» $(1958,42)$.

El maquinismo trajo un avance considerable — continuaba nuestro autor-: el maquinismo libera las fuerzas económicas, y así la revolución industrial «en pocos años logró lo que antes se había tardado siglos, si no milenios. La producción de los bienes de la tierra decuplicó, centuplicó a veces. Los hombres tuvieron más oportunidades que nunca para comer, alimentarse, albergarse y viajar, siempre en mejores condiciones y a mejores precios. Otro espectacular triunfo del maquinismo se registró en el aumento de la población mundial. [...] La gente se vio más alimentada y mejor atendida desde el punto de vista higiénico. Los éxitos del maquinismo hicieron concebir un ideal puramente económico. 'Enriquecerse' fue la consigna del momento» $(1958,43)$.

La palabra maquinismo se incorpora al $D R A E$ en 1936: 'empleo predominante de las máquinas en la industria moderna'.

mutualismo. Al exponer a los teóricos del socialismo, J. Vicens define el mutualismo en tanto 'reciprocidad de servicios': Pierre Proudhon «alentó de modo extraordinario la idea del mutualismo (la reciprocidad de servicios)» $(1952,390)$.

La tercera edición del llamado Diccionario manual de la Academia - en verdad poco manual en esta edición- define ya nuestra voz, a saber: 'sistema de prestaciones mutuas, desarrollado a partir de fines del s. XVIII' (1984).

obrero, clase obrera. Jaume Vicens estudió —en particular en sus últimos años- el conjunto situacional a que dio lugar la industrialización, la burguesía y el obrerismo, y por ej. (esta vez más tempranamente) caracterizaba la vida del obrero: «La esclavitud dejó de existir pacíficamente hacia 1870. Pero el obrero era distinto. Apenas si se le consideraba más que como un elemento accesorio para hacer funcionar las máquinas, $\mathrm{y}$ en tal concepto tanto importaba un hombre, como una mujer, como un niño. La [N]aturaleza, que había instituido la propiedad, había instaurado también la desigualdad social, y era preciso conformarse a sus reglas. Esto era lo que se pensaba, y lo que además se ponía en práctica desde que las constituciones liberales, a partir de la francesa de 1791 [...] 
habían derogado las coaliciones obreras. El individuo, solo, ante el Estado; mejor dicho, ante el industrial. Y ello equivalía a aceptar las más onerosas condiciones de trabajo, a veces incluso impropias de un ser humano» $(1952,369)$.

Otras referencias al obrero y la clase obrera de nuestro autor dicen así: «La Revolución industrial, creadora del maquinismo, concentra en la fábrica un número creciente de obreros. La máquina necesita servidores. [...] Así se constituye el obrero moderno, sin más bienes de fortuna que su capacidad de trabajo y el salario que obtiene del mismo. [...] Algunos puntos son comunes a todos los países europeos respecto a la situación de la clase obrera», que son: a) excesiva duración de la jornada laboral; b) trabajo en malas condiciones; c) explotación del trabajo de mujeres y niños; d) salario bajo; e) paro forzoso; f) inseguridad laboral; g) insolidaridad social (1958, 44-46).

El significado con que aparece la voz obrero en el Diccionario de Autoridades es el de 'el oficial que trabaja por jornál en las obras de las casas, y en las labores del campo'; en 1899 el $D R A E$ define por tal a la 'persona que trabaja en un oficio ú obra de manos'. Antes, Ramón Joaquín Domínguez tenía como obrero al 'operario, jornalero, trabajador: y especialmente, el oficial que trabaja por jornal en las obras de los edificios, ó en las labores del campo'.

Además el propio DRAE llama al obrero 'trabajador manual retribuído' en 1925, y la primera versión (1927) del Diccionario académico manual lleva la entrada obrerismo: "régimen económico fundado en el predominio del trabajo obrero como elemento de producción y creador de riqueza'; 'conjunto de los obreros, considerado como entidad económica'. Estas acepciones de la palabra que se hallaban incorporadas provisionalmente en el Diccionario manual, se incorporan definitivamente al Diccionario común de la Academia en la entonces inmediata edición de 1936/1939.

pequeña burguesía. Nuestro autor caracteriza asimismo a este que llama elemento social «importante por su número y su ideología»: se trata de «la pequeña burguesía, [e]l ciudadano medio, situado tanto en el orden social como en el económico, entre los burgueses y los obreros».

«Es un hecho evidente (escribe asimismo Jaime Vicens) que la mentalidad pequeño-burguesa fué más reacia al deseo de participar en la producción que al de poseer bienes de consumo. [...] Los pequeños burgueses [...,] vinculados como sus congéneres mayores a las dulces ideas de propiedad y libertad, las interpretaban de modo harto distinto: propiedad, sí, pero redistribuída, a fin de que no fuese factible constituir grandes fortunas que desequilibrasen el normal juego de la sociedad; libertad, también, pero para todos, desde el aristócrata al más humilde obrero. Sin embargo la libertad debía ser asimismo ordenada, regulada. Por esta causa, en los períodos de pacificación social la pequeña burguesía fué el más obstinado ariete para la reforma democrática del Estado; en cambio ante el desorden, reaccionó sumándose a las filas de los ideales burgueses. Este juego de balancín explica el mecanismo íntimo de los cambios políticos en Europa de 1870 a 1914, y aun hasta 1939» (1952, 370-371).

Cabe recordar que Balzac escribió la novela y usó la expresión «Los pequeños burgueses»—de «La comedia humana»—, y que en ella se refiere a «las in- 
finitas pequeñeces de la existencia burguesa», así como uno de los personajes enuncia que «la burguesía tiene la obligación de las altas virtudes más que la nobleza, a la que debe remplazar» (Balzac 1971).

positivismo (en las ciencias, el). «El positivismo en las ciencias emprendió una doble tarea:la de estructurar los atisbos geniales de los románticos y la de proseguir por la senda de los progresos realizados. Justo es decir que en esta última misión superó en mucho a la primera. [...] En todo caso la marcha de las ciencias se trocó en frenético galopar. Lo sabido ayer parecía al día siguiente avejentado, y nadie se preocupaba de dar una eficiente vertebración filosófica al conjunto de los conocimientos adquiridos. Mejor dicho, se sostuvo que ellos mismos daban su razón de ser (cientifismo); o bien se crearon esquemas mentales en que el materialismo determinista fué alcanzando carta de primacía (1952, 402).

Desde el punto de vista científico acaba por imponerse —enseña también Vicens - «el POSITIVISMO. Defendido como filosofía del progreso natural, el positivismo propugna la duda sistemática ante la ausencia de datos científicos, el desprecio de toda tradición, la ignorancia de lo sobrenatural y el aferrarse a la realidad de la vida. Así el positivismo se convierte en pensamiento de la burguesía de fines de siglo, a la que confiere un aire pedantesco, suficiente y cursi» $(1945 / 1960,472-473)$.

Esta voz positivismo se incorpora en la acepción que nos importa al DRAE de 1884: 'sistema de filosofía fundado únicamente en el método experimental, y que rechaza toda noción a priori y todo concepto universal y absoluto'; Pagés lo repite a la letra.

proletariado obrero; proletariado social; proletariado industrial. Nuestro autor designa así a 'la gente que vive de su trabajo en la industria, el comercio o la agricultura'. «Braceros y arrendatarios a corto plazo - continúa - forman los proletarios del campo, gente sin tierra o con terrenos insuficientes para la vida de la familia. Pero el tipo cabal de proletario se encuentra en las ciudades y la industria. [...] El empresario capitalista considera al obrero como un elemento más de su organización industrial o comercial, como un factor «material» de la producción. Lo retribuye con un «salario» determinado y procura sacar de él el máximo rendimiento, aunque vulnere las leyes divinas y humanas. Este hecho explica la desmoralización del obrero y el planteamiento del problema social» $(1943,555)$.

Vicens define también de manera expresa que «el proletariado, en su acepción específica, [...] es 'el obrero que no posee otros bienes que su trabajo personal' ». E ilustra ahora: «La concentración industrial y la política de salarios más remuneradores en la industria que en la agricultura, atrajo a las ciudades masas cada día crecientes de población campesina. Este fenómeno tuvo consecuencias decisivas en el orden social y cultural del Diecinueve. En la gran ciudad, producto [...] de la potencialidad económica burguesa, se consumó la desvinculación entre el hombre y el suelo, se formó el proletariado obrero, se impuso el cosmopolitismo, se fomentó el mercado de lujo y de capricho y aparecieron escuelas intelectuales, artísticas y literarias desarraigadas del ambiente na- 
cional, extravagantes a veces en su forma y disgregadoras casi siempre en el fondo. La cultura del Diecinueve fué llevada a su apogeo por la ciudad; ésta impuso sus gustos, sus ideales y sus normas, y el campo las admitió, sugestionado por las maravillas de la gran vida urbana» (1952, 386-387).

Otras precisiones que da Vicens (y que le llevan a emplear la fórmula verbal proletariado social), dicen que la constitución del proletariado «como clase social poderosa —el Cuarto Estado - no tuvo lugar hasta mediados del siglo XIX, cuando se estableció el régimen del Gran Capitalismo y la población europea experimentó [... vertiginoso aumento]. En este sentido, masa y proletariado social se confundieron muy pronto, ya que la evolución capitalista tendía a concentrar la riqueza en manos de un núcleo reducido de personas, mientras se acrecentaba el número de aquellas que habían de vivir de su exclusivo trabajo, ya empleadas en las grandes fábricas, ya en las instituciones comerciales del Gran Capitalismo. De esta manera, entraron a formar parte del proletariado, no sólo los antiguos obreros y artesanos, sino las nuevas masas de población campesina que acudieron a las ciudades para ocuparse en fábricas y talleres» (1952, 387-388).

«El proletariado industrial — escribe asimismo nuestro autor- $-[. .$.$] aparece$ desde fines del siglo XVII cuando se organiza el mundo capitalista en vistas a una producción considerable de bienes a bajo precio» $(1958,44)$.

El vocablo proletariado lo define el Diccionario común académico de 1914 en tanto referido a una 'clase social', y en el mismo texto proletario es 'el que no tiene bienes ningunos', o un 'individuo de la clase indigente'.

Restauración. En términos histórico-europeos, Jaume Vicens se refiere a la situación histórica del Ochocientos designada como Restauración, cuyos principios básicos son «tradicionalismo, legitimidad, religiosidad y misticismo», y expone cómo «las sociedades humanas se dividieron en dos grupos de ideología distinta: los conservadores, que alimentaban la ideología de la Restauración, y los liberales, partidarios de la Revolución en sus formas moderadas o radicales. [...] Hubo dos tipos de elementos revolucionarios, [...] de un lado los que pretendían la reivindicación de los derechos de las colectividades nacionales; de otro los que querían afirmar los derechos del individuo respecto al Estado y la Iglesia. La primera corriente [...] condujo a la formación del nacionalismo; la segunda es la liberal en sentido propio. Para la Restauración ambas tenían el mismo carácter revolucionario. Las dos corrientes se presentan muchas veces unidas o bien ofrecen muchas zonas de contacto» $(1943,492-493)$.

«En 1815 - manifiesta J. Vicens en otro momento- parecía contenida la obra disgregadora de la Revolución. Las cancillerías organizaron la vida política de los Estados europeos de conformidad con los principios tradicionales y legitimistas; tal fué la esencia de la Restauración. Pero en realidad las corrientes revolucionarias continuaban desarrollándose en la intimidad de los hechos sociales. De un lado la ideología liberal, tanto en el campo económico como en el político, halló su definitiva encarnación en las aspiraciones de la clase burguesa de casi todos los países de Europa; de otro el sentimiento romántico, robustecido por las corrientes historicistas, prendió en los corazones de aquellos pueblos 
disgregados o absorbidos por otros en el transcurso de la evolución histórica moderna, despertando en ellos el deseo de reconstruir su nacionalidad, ya en el aspecto cultural, ya en el político. Liberalismo y nacionalismo - fenómenos revolucionarios- destruyeron las últimas resistencias orgánicas del viejo orden europeo, concretadas en el sistema de la Restauración» $(1952,278)$.

Una exposición más elemental pero sumamente clara, concreta qué debe entenderse por «Restauración» en términos (insistimos) histórico-europeos contemporáneos; dice nuestro autor en referencia inicial al Congreso de Viena que «el principio que se aplicó fue la RESTAURACIÓN DE LA LEGITIMIDAD MONÁRQUICA. [...] La victoria de los Aliados desencadenó una oleada antirrevolucionaria en todos los países. No sólo se restableció la legitimidad monárquica, sino que se devolvió a la Iglesia la plenitud de sus derechos. Los poetas ensalzaron el Catolicismo y combatieron la Revolución. Este movimiento cultural y político se conoce con el nombre de RESTAURACIÓN. Ahora bien, muy pronto se tuvo la convicción de que en muchos puntos sobrevivía el espíritu revolucionario, que se manifestaba ya en forma liberal, ya en forma nacionalista, o bien conjuntamente. Las sociedades secretas como la de los carbonarios y las logias masónicas, apoyaban a los descontentos y preparaban el triunfo de sus ideas (1945/1960, 432-433).

Se denomina Restauración - decía en fin Jaume Vicens Vives en el último libro que pudo escribir en su corta vida - al período en que «se restauró el poder de la monarquía y la influencia del Catolicismo» $(1960,238)$.

religiosidad, repliegue o crisis de la. «La peor crisis experimentada por la vida religiosa a lo largo de la historia —entendía Vicens - se registra en el siglo XIX. Muchos factores contribuyeron a desencadenarla, entre los cuales retienen el mayor interés las emigraciones de los campesinos a las ciudades, la constitución del proletariado, la admisión del liberalismo como dogma político, el desarrollo del materialismo y del ateísmo y la tendencia del siglo al positivismo científico. [...] Hubo querellas científicas, como la suscitada por el evolucionismo, que conmovieron profundamente las convicciones religiosas de la burguesía. El materialismo histórico junto con el anticlericalismo, apartaron a los obreros de la Iglesia, especialmente en los países latinos. Sin embargo de las entrañas del idealismo conservador y del Romanticismo surgieron fuerzas de recuperación para la Iglesia católica. Este proceso se revela en el esplendor alcanzado por el Pontificado con las figuras de Pío IX (1845-1878) y León XIII (1878-1903)» (1945/1952, 469; dedica unas páginas específicas a «La Iglesia española en el siglo XIX» José María Jover: 1964, 263-266 y n.).

Romanticismo, el. «En sus primeras fases - interpretaba Vicens-, el Romanticismo había sido un elemento de choque contra el racionalismo de la Enciclopedia, y en este sentido constituyó una de las plataformas ideológicas de la Restauración. Muchos de los liberales veían en esa corriente una actitud espiritual aliada de la Santa Alianza y la política contrarrevolucionaria de Metternich. Pero en su fase final, el Romanticismo marchó al lado del liberalismo. Este fenómeno tiene una doble explicación. De un lado el Romanticismo ponderó en demasía lo irracional y lo individual, la revuelta del espíritu contra toda norma; cayó en definitiva en una disgregación caótica de los valores clásicos [...]. Por 
otra parte la consolidación del Romanticismo se consumó en Francia, y desde este país la nueva corriente irradió a las penínsulas mediterráneas, fomentando en ellas el aspecto individualista y radical [...]. Es sumamente importante la coincidencia del triunfo del Romanticismo y del liberalismo en el Occidente de Europa, que se registró aproximadamente entre 1828 y 1833. Sin embargo al hablar del Romanticismo siempre es preciso distinguir entre sus dos corrientes esenciales: la conservadora-histórica, que recoge los fenómenos iniciales, aun equilibrados, de lo romántico, y la liberal-progresista, que se apoya en el naturalismo del siglo XVIII. [...] El triunfo del Romanticismo coincide con un recrudecimiento de los factores revolucionarios, ya liberales, ya nacionales» $(1952,297$ 299).

$\mathrm{Al}$ tratar en un epígrafe de «la ciencia romántica», Jaume Vicens caracteriza que el Romanticismo «contempló los fenómenos de la Naturaleza y los hechos humanos en el seno de grandes construcciones teóricas, cuyos detalles dejó para la comprobación experimental. Lo intuitivo adquirió una plaza singular en lo metodológico, y a veces gracias al rasgo del genio se profundizó en la explicación de las intimidades del Universo. Otras veces por el contrario el ambiente romántico produjo exageraciones conceptuales que pesaron gravemente sobre el proceso ulterior de la ciencia. [...] Donde el Romanticismo triunfó plenamente fué en la revaloración del factor histórico como elemento indispensable para conocer el presente. Por vez primera se situó a la Edad Media en el lugar que le correspondía en la elaboración de la cultura occidental, e incluso se pecó por exceso al desdibujar lo tosco y bárbaro de aquel período y acentuar la nota caballeresca, liberal y y democrática del mismo. Pero prescindiendo de tales errores, la Historia salió robustecida por el contacto con el espíritu romántico» $(1952,401)$.

De manera más elemental, nuestro autor hizo también esta otra caracterización: «Como movimiento cultural, el Romanticismo se propuso la rehabilitación del espíritu y el genio de las naciones, revelado en sus costumbres y tradiciones (folklore), en su arte, en su derecho e instituciones propias y, sobre todo, en su lengua (y de aquí los numerosos renacimientos en las literaturas europeas [ ) ... El Romanticismo] preconizó la autonomía artística, el desprecio de toda norma, la manifestación del yo personal, la satisfacción de lo apasionado y vital. Lo primitivo, lo bárbaro, lo sanguinario; el conquistador, el pirata y el bandolero fueron temas constantes en la musa y la paleta de los románticos» (1945/1960, 470471).

Y por igual elementalmente, Vicens expuso que el Romanticismo consistió en «la manifestación del hombre con voluntad de acción, libertad de sentimientos y dominio de la $[\mathrm{N}]$ aturaleza $[, \ldots]$ llegando en sus momentos de apogeo a la apología desenfrenada del singularismo humano contra todos los valores de la sociedad» $(1954 / 1960,217)$.

siglo XIX, unidad en la evolución cultural del. Interpreta y expone nuestro autor: «Cuatro siglos después de su descubrimiento, los valores implicados en el Renacimiento llegan a su ápice en el Occidente de Europa; el hombre es libre en sus relaciones con toda clase de autoridad política, científica y religiosa; el hombre domina y conquista la [N]aturaleza, sujetándola a su capricho para el 
progreso de la sociedad. Estos dos principios determinan el carácter unitario de la evolución cultural del siglo XIX, realizado por una clase social, la burguesía, y una porción del mundo, Europa occidental, en una dirección precisa: la liberación del hombre por la técnica y la máquina. [...En cuanto a romanticismo y positivismo, constituyen] dos caras de la misma medalla: el ímpetu sentimental y el rigorismo científico con que progresan velozmente las sociedades occidentales, hasta llegar a una tensión máxima de desquiciamiento: el imperialismo económico y el gran capitalismo» (1945/1960, 462).

socialismo científico. En un epígrafe sobre «Los socialistas proletarios y el socialismo científico» expone nuestro autor: «El marxismo introdujo el concepto de lucha de clases, la filosofía del materialismo dialéctico, la organización políticointernacional de los obreros y la conquista del poder por la violencia. Estas ideas se popularizaron y guiaron la acción subversiva de las masas europeas hasta la actualidad [1952 .... La mayor aportación de Marx a la cuestión social del siglo XIX fué la mesiánica idea de que el proletariado era la casta elegida para regenerar el mundo pervertido por el capitalismo y la burguesía. Los descontentos de toda clase - unos por inferioridad mental; otros por resentimientos sociales; los terceros por real debilidad material-, se acogieron bajo los rígidos pliegues de una tan simple bandera. Y así poco a poco la masa obrera europea fué perdiendo el respeto que hasta 1871 había atribuído a la palabra libertad. En adelante sería preciso que impusiera su consigna: una igualdad que se entendía en el sentido de apropiarse los medios de producción, distribuir entre todos las riquezas de la Tierra y llegar a un clima de igualdad en que el mundo no conocería explotadores y explotados» $(1952,392)$.

La situación de un proletariado sometido a la ley de la oferta y la demanda «provocó desde principios del siglo XIX - expuso asimismo Vicens- una conciencia colectiva entre los obreros y una corriente de ideas que preconizaba la intervención del Estado en la vida económica del país, como medio para llegar a la eliminación del capital privado o su posesión por la comunidad (socialismo). Los primitivos socialistas creyeron que el género humano, una vez libre de la congelación y explotación del capitalismo, conseguría la paz y la felicidad» $(1954 / 1960,222)$.

El DRAE de 1852 define el socialismo como el 'sistema que se propone principalmente una nueva distribucion general de bienes'; la edición de 1884 hace esta otra definición quizá más ideológicamente conservadora: 'sistema de organización social que supone derivados de la colectividad los derechos individuales, y atribuye al [E]stado la potestad de modificar las condiciones de la vida civil'. La subsiguiente edición de 1925 modifica el texto así: 'sistema de organización social que supone derivados de la colectividad los derechos individuales, y atribuye al Estado absoluta potestad de ordenar las condiciones de la vida civil, económica y política, extremando la preponderancia del interés colectivo sobre el particular'; en fin en 2001 socialismo es en una de sus acepciones y siempre en el texto del $D R A E$, el 'sistema de organización social y económico [sic] basado en la propiedad y administración colectiva o estatal de los medios de producción y en la regulación por el Estado de las actividades económicas y sociales, y la distribución de los bienes'. 
supercapitalismo. Vicens se refiere a esta designación al decir: «Después de las profundas transformaciones técnicas registradas en el umbral del siglo XX [...], el capitalismo entró en una fase de máxima pujanza [...]. Esta etapa recibe el nombre de economía supercapitalista, en cuanto se acentuaron los rasgos propios del capitalismo, y también de capitalismo financiero, porque la producción y la distribución de mercancúas entraron bajo la tutela de las entidades poseedoras de capitales: los bancos, en primer lugar, y en última instancia el Estado» $(1958,51)$.

trust. Según queda registrado, en varios de los textos que venimos citando hace empleo Jaume Vicens de los vocablos cártel y trust (e. gr., 1943, 552; 1958, 55); sólo desde la primera edición del Diccionario manual de la Academia (1927) figura la palabra a la que atendemos ahora, en tanto voz inglesa cuyo significado es el de 'monopolio, asociación de especuladores de un producto para ponerse de acuerdo sobre el precio y demás condiciones de venta', y ha sido reciente y tardíamente cuando el $D R A E$ ha incorporado la voz. En nuestros días el mencionado $D E A$ hace esta definición: 'unión de sociedades o empresas cuyo fin es ejercer una influencia preponderante en un sector económico'. De la palabra hicieron empleo ya Pío Baroja, Azorín, ...

universalismo como carácter de la historia del siglo $\mathrm{XIX}$.«El progreso en las comunicaciones -ilustra nuestro autor- (ferrocarriles, teléfonos, telégrafo, automóviles, aviación, radio, etc.) aproxima a los pueblos e instituye la verdadera comunidad de naciones. De aquí deriva otro de los caracteres de la historia del siglo XIX: el universalismo. Durante el siglo XIX, de 1815 a 1914, la revolución en el sistema de comunicaciones y transportes es profunda, radical y general» $(1943,549)$.

\section{BIBLIOGRAFÍA}

BalzaC, H. de (1971): La comedia humana, Barcelona, Plaza \& Janés, VI.

JOVER, José María [y otros autores] (1964): España moderna y contemporánea, Barcelona, Teide.

Maravall, José Antonio (1973): «Dos términos de la vida económica: la evolución de los vocablos «industria» y «fábrica»», Cuadernos Hispanoamericanos, 280-282 (separata paginada 1-30).

MuÑoz LloRet, Josep M., ed. (2010): Álbum Jaume Vicens i Vives, Barcelona, Ediciones Vicens Vives.

Vicens Vives, Jaime (1943): Tiempos Modernos (= Historia General, III), Barcelona, Apolo.

- (1945/1960): Polis. Historia Universal, Barcelona, Edit. Vicens-Vives (1960; en colaboración).

- (1952): Historia General Moderna, II, Barcelona, Montaner y Simón.

- (1954/1960): Ars. Historia del arte y de la cultura, Barcelona, Teide.

- (1958): El problema social, Barcelona, Teide [con la colaboración de Jorge Pérez Ballestar]. 
- (1960): Cives. Historia Universal y de España, Barcelona, Teide.

- (2010): Atlas de la evolución de la Humanidad, Barcelona, Edit. Vicens Vives. 